\title{
A description and summary of the Antarctic Humpback Whale Catalogue
}

\author{
Judith Allen*, Carole Carlson*^and Peter T. Stevick*,+ \\ Contacte-mail: jallen@coa.edu
}

\begin{abstract}
The Antarctic Humpback Whale Catalogue (AHWC) is an international collaborative project investigating movement patterns of humpback whales in the Southern Ocean and corresponding lower latitude waters. The collection contains records contributed by 261 researchers and opportunistic sources. Photographs come from all of the Antarctic management areas, the feeding grounds in southern Chile and also most of the known or suspected low-latitude breeding areas and span more than two decades. This allows comparisons to be made over all of the major regions used by Southern Hemisphere humpback whales. The fluke, left dorsal fin/flank and right dorsal fin/flank collections represent 3,655, 413 and 407 individual whales respectively. There were 194 individuals resighted in more than one year, and 82 individuals resighted in more than one region. Resightings document movement along the western coast of South America and movement between the Antarctic Peninsula and western coast of South America and Central America. A single individual from Brazil was resighted off South Georgia, representing the first documented link between the Brazilian breeding ground and any feeding area. A second individual from Brazil was resighted off Madagascar, documenting long distance movement of a female between non-adjacent breeding areas. Resightings also include two matches between American Samoa and the Antarctic Peninsula, documenting the first known feeding site for American Somoa and setting a new long distance seasonal migration record. Three matches between Sector V and eastern Australia support earlier evidence provided by Discovery tags. Multiple resightings of individuals in the Antarctic Peninsula during more than one season indicate that humpback whales in this area show some degree of regional feeding area fidelity. The AHWC provides a powerful non-lethal and non-invasive tool for investigating the movements and population structure of the whales utilising the Southern Ocean Sanctuary. Through this methodical, coordinated comparison and maintenance of collections from across the hemisphere, large-scale movement patterns may be examined, both within the Antarctic, and from the Antarctic to breeding grounds at low latitudes.
\end{abstract}

KEYWORDS: HUMPBACK WHALE; SOUTHERN HEMISPHERE; PHOTO-IDENTIFICATION

\section{INTRODUCTION}

The Antarctic Humpback Whale Catalogue (AHWC) is an international collaborative project investigating movement patterns of humpback whales (Megaptera novaeangliae) in the Southern Ocean and corresponding lower latitude waters. College of the Atlantic (COA) has maintained a collection of humpback whale identification photographs from the Antarctic since 1987 with initial contributions coming primarily from collaborating scientists and opportunistic sources from South America and the Antarctic Peninsula. Early resightings confirmed migration of humpbacks between the Peninsula and the western coast of South America (Stone et al., 1990). Since 1998, the International Whaling Commission (IWC) has provided support for the expansion of this catalogue to include dorsal fins and for the development of a searchable online database.

The collection has grown substantially in size and geographic scope. It now contains records of individual whales from throughout the Southern Ocean Sanctuary, in all of the Antarctic management areas, the feeding grounds in southern Chile and also in most of the known or suspected low-latitude breeding areas, allowing comparisons to be made over all of the major regions used by Southern Hemisphere humpback whales and spanning more than two decades. The collection has been internationally collaborative; 261 researchers and opportunistic sources have contributed photographs to these analyses.

The AHWC sets out to:

(1) compile identification photographs of the ventral fluke and the left and right flanks of humpback whales collected by collaborating researchers or from opportunistic sources;

(2) create and maintain relational databases for associated field data;

(3) scan and archive all images and link these to the databases;

(4) report to contributors on completion of photo comparison and work with these collaborators to disseminate findings; and

(5) provide online access to the photographic collection. In this paper the organisation and maintenance of the AHWC and the statuses of these collections is reported on.

\section{METHODS}

Photograph processing and archive

Photographs have been submitted as prints, slides, negatives or in electronic format. All catalogued photos were digitised and stored electronically. Images not submitted electronically were scanned at 300dpi and stored in TIFF format to avoid losses in quality resulting from image compression. Electronic submissions were archived in their original format; copies of these were cropped and adjusted as required and these copies used for analysis. A unique serial number was assigned to each image. The individual identification number and serial number served as a file name, linking each photograph to all related database records. The best images of each individual were additionally stored in an iMatch database that was used for image comparison analysis. 
Photographs to be included on the web page were additionally stored at 100dpi in JPG format. This resolution is adequate for on-screen resolution, but not for reproduction, providing data security for collaborators, while the small file size resulting from the compressed format and low resolution facilitates web operations. The low-resolution images used on the website were stored in a Filemaker Pro database on a web server to make these available to the web page. All electronic images and databases were stored on a network file server and backed up to a remote tape drive daily.

\section{Photographic collections}

Individual humpback whales were identified by natural markings and permanent scars. Humpback whales may be identified by features on several areas of the body. The most commonly used are the shape and markings of the ventral side of the flukes or the dorsal fin and flank (Katona and Whitehead, 1981). Photographs of three body regions, the fluke, the left side of the dorsal fin and flank, and the right side of the dorsal fin and flank, were maintained separately within the catalogue.

Photographic comparison was conducted following the model developed by Katona and Beard (1990) modified for use with electronic images. The best photographs of each individual were stored in the $i$ Match database, which was continually updated as better photographs were received. The image management software iMatch allowed the user to assign categories, subcategories and properties to images. Assigned categories include geographic area, ventral fluke pattern type (five categories, 1-5, ranging from all white to all black) with subcategories within types indicating specific arrangement of pigmentation, and categories indicating presence of features such as orca scars, barnacle scars and injuries. Categories may be viewed alone or in combination. While area sighted may be used as a search criterion, new animals were compared to catalogued whales from all other regions without regard to anticipated population structuring or distance between sighting locations. Data such as the years that an individual was sighted may be associated with images as properties. Combined, categories and properties provide convenient and flexible means to view specific sub-sets of the collection without compromising comprehensive comparison.

New photographs were either printed for comparison with the on-screen catalogue, or the new image was displayed on a separate monitor allowing catalogue images to be displayed in full-screen format. Before comparison commenced each whale represented by a fluke photograph was assigned a pattern type. This individual was then compared to all of the individuals in the collection that had been assigned the same pigment type and to those assigned one type darker and one type lighter. Previously, new individuals had been compared to all individuals in the catalogue without regard to pigment type. With the increasing size of the collection and resulting time required for comparison of each new individual this became impractical and, with the ease of sorting allowed by the $i$ Match software, the comparison with the most dissimilar types was discontinued. While an individual assigned a type of 3 , for example, is very unlikely to be categorised from a different photograph as a type 5 or a type 1 , this procedure slightly increases the risk of false negative errors in identification. The dorsal fin collections are not yet large enough to require this type of selection and each new individual was compared to all individuals currently in the catalogue. A system for grouping animals with similar dorsal fin appearance using characteristics such as fin shape or flank pigmentation could easily be developed if the collection became large enough that one were needed.

All new photographs were compared to the collection twice by different technicians. Photographs that matched a previously identified whale was assigned that catalogue identification number; photographs which represent a new animal were assigned a new identification number, added to the catalogue and included in all future comparisons. The iMatch software allows new photographs to be added to the catalogue immediately upon completion of photocomparison, further speeding analysis.

Photographic quality was coded by methods developed by Friday et al. (2000). As inclusion of poorer quality photographs increases the probability of errors in identification and resulting biases in analyses (Friday et al., 2008; Stevick et al., 2001) as well as substantially increasing the time required to make comparisons. The minimum quality of photographs accepted into the catalogue has been made more restrictive, and some photographs that show identifiable markings and may be included in the collections of collaborators were excluded from the catalogue.

\section{Databases}

Accompanying data for all photographs are stored in a relational database (MS FoxPro). The fluke and dorsal/flank collections are combined in a single data file but the area of the body represented in the photograph is distinguished by use of a data field indicating fluke or dorsal type (right or left), to facilitate analysis of the three collections independently. Where photographs of more than one body region were obtained from an individual during the same sighting, and identified as such by the contributor, the same identification number was applied to all photographs of that animal for convenience. However, analyses were only conducted by one body area; no attempt was made to integrate these in specific investigations. Additional information stored included the identity of the contributor, date and location to the degree of precision provided by the contributor, roll and frame (or contributor's image file name for electronic images), any id number supplied by the contributor corresponding to their cataloguing system and photographic quality code. Images and data accessed by the web page were stored in a Filemaker Pro database, hosted on a local web server.

\section{Reporting}

A standardised data report was issued to all contributors on completion of cataloguing of submissions. The report included the catalogue number assigned and the data submitted with the photographs as it is recorded in the file. The year and region are provided for any previous sighting history along with the contributor. Contact information for contributors of these previous sightings was provided to facilitate further communication between the contributors, allowing them to exchange additional data if they chose to do so. To assist collaborators in sharing significant findings, periodic updates of sightings histories were provided, along with reports of potentially important resightings of whales previously submitted. AHWC personnel also assist collaborators in presenting and publishing these findings.

\section{Online access}

In order to facilitate access by contributors to the collection, an online Antarctic Catalogue web page was developed ( . Both fluke and dorsal fin/flank collections are currently available, although a search criterion allowing the user to 
specify dorsal fin/flank has not yet been added. Users are able to $\log$ in and search by pigmentation pattern, geographic area, or catalogue number. Only those photographs for which permission has been received to publish electronically are included in the online collection. Images displayed are identified by catalogue number and the contact organisation for the contributor. No additional data are available online. Photos submitted by the IWC, Allied Whale researchers, and opportunistic sources are accessible to the general public. A login-security system restricts access to the remainder of the collection to contributors only. Access to photographs submitted by other contributors is restricted unless otherwise indicated. Users are advised of the security protocol of the project, whereby they are not permitted to share their password with others or reuse photographs or other information without permission. Instructions including the website address, login and password are sent to contributors with the data report. Users may search either a public database or a secure contributor-only database. Before accessing either database, users must agree to terms of use (see Appendix 1) which include not publishing or reproducing information without written consent.

\section{RESULTS}

\section{Photographic collections}

The AHWC contained 7,107 photographs as of May 2010. Each photograph is included in one of three collections: fluke; right dorsal fin/flank; or left dorsal fin/flank. The fluke photographic collection consists of 6,083 photographs of 3,665 individual whales. Of the $>4,000$ fluke photographs maintained in the iMatch database and used for photographic comparison, $4.6 \%$ were coded as the poorest quality (3-), with $9.5 \%$ coded as 3+ (Friday et al., 2000). While these poor quality photographs make it more difficult to correctly identify an individual, leading to more potential for falsepositive errors in identification (Stevick et al., 2001) and potential biases in estimation of population parameters if they are included in calculations (Friday et al., 2008), they contain adequate information to make unambiguous identification from an appropriate corresponding photograph, and are therefore retained for their use in documenting movement of individual animals. The right dorsal fin/flank collection consists of 521 photographs of 413 individuals. The left dorsal fin/flank collection consists of 503 photographs of 407 individuals.

Photographs submitted from high-latitude feeding areas include IWC Antarctic Areas II, III, IV, V and VI and coastal water of Chile, as well as the Antarctic Peninsula (which spans both Sectors I and II). Photographs submitted from low-latitude breeding regions include areas off South America (Peru, Ecuador, Colombia and Brazil), Central America (Costa Rica), Africa (Gabon), Australia and Oceania (Table 1, Fig. 1). As of May 2010, there were 310 individuals resighted in more than one year and 128 individuals resighted in more than one region (Table 2).

Resightings between regions document movement along the western coast of South America and movement between the Antarctic Peninsula and western coast of South America between Peru, Ecuador, Colombia, Panama and Costa Rica (16 matches) (Rasmussen et al., 2007; Stevick et al., 2004; Stone et al., 1990). The matches to Costa Rica (Rasmussen et al., 2007) mark the first documentation of Northern and Southern Hemisphere populations of humpback whales using the same breeding and calving ground during different seasons. Resightings to the Antarctic Peninsula differed dramatically between eastern and western South America (Stevick et al., 2004). No individuals from Brazil were resighted in either the Antarctic Peninsula or off western South America. A single individual from Brazil however was

Table 1

Fluke and dorsal photographic collections, by region. Individual whales that have been identified in multiple regions are listed in each region, so the total number of individuals listed may not be the same as the column totals.

\begin{tabular}{|c|c|c|c|c|c|c|}
\hline \multirow[b]{2}{*}{ Region } & \multicolumn{2}{|c|}{ Fluke } & \multicolumn{2}{|c|}{ Right dorsal } & \multicolumn{2}{|c|}{ Left dorsal } \\
\hline & Photos & No. whales & Photos & No. whales & Photos & No. whales \\
\hline Antarctic II-VI total & 478 & 296 & 145 & 110 & 169 & 125 \\
\hline Sector II* & 30 & 22 & - & - & - & - \\
\hline Sector III & 196 & 117 & 16 & 13 & 26 & 15 \\
\hline Sector IV & 168 & 108 & 82 & 59 & 72 & 63 \\
\hline Sector VI & 11 & 7 & 17 & 12 & 18 & 12 \\
\hline Gabon & 94 & 78 & - & - & - & - \\
\hline St. Helena & 3 & 2 & - & - & - & - \\
\hline Ghana & 1 & 1 & - & - & - & - \\
\hline South Africa & 11 & 7 & - & - & - & - \\
\hline Brazil & 1,524 & 888 & 2 & 2 & 5 & 5 \\
\hline Chile & 83 & 77 & - & - & - & - \\
\hline Peru/Ecuador/Colombia/ Panama/Costa Rica & 1,075 & 767 & 72 & 30 & 64 & 26 \\
\hline Tahiti & 1 & 1 & - & - & - & - \\
\hline New Zealand & 2 & 1 & - & - & - & - \\
\hline Tonga & 24 & 18 & - & - & - & - \\
\hline French Polynesia & 2 & 2 & - & - & - & - \\
\hline Madagascar & 247 & 226 & - & - & - & - \\
\hline E Australia & 34 & 27 & 1 & 1 & 2 & 1 \\
\hline W Australia & 317 & 242 & 251 & 236 & 221 & 213 \\
\hline Totals & 6,083 & 3,665 & 521 & 413 & 503 & 407 \\
\hline
\end{tabular}

*Antarctic Peninsula includes individuals identified along the coast of the AP and South Shetland Islands as far to the east as the South Orkney Islands $\left(45^{\circ} \mathrm{W}\right)$. Area II includes individuals identified east of the South Orkney Islands to $0^{\circ}$ (see Stevick, 2005). 
Table 2

Number of individual whales identified by fluke photographs in each region, the number of individuals resighted in each region in more than one year, and the distribution of resightings between regions.

\begin{tabular}{lccccc}
\hline & & & & \multicolumn{3}{c}{ Between region re-sightings } \\
\cline { 5 - 7 } Region & No. whales & $\begin{array}{c}\text { Between year } \\
\text { resightings }\end{array}$ & Pe/Ec/Co/Pa/CR & AP & Sector II \\
\hline Antarctic Peninsula & 995 & 121 & - & - & - \\
$\quad$ Sector II & 22 & - & - & 1 & - \\
Sector III & 117 & - & - & - & - \\
Sector IV & 108 & - & - & - & - \\
Sector V & 40 & - & - & - & - \\
Sector VI & 7 & - & - & - & - \\
Gabon & 78 & - & - & - & - \\
Ghana & 1 & - & - & - & - \\
South Africa & 7 & - & - & - & - \\
Saint Helena & 2 & - & - & - & - \\
Brazil & 888 & 42 & - & - & - \\
Chile & 77 & 5 & - & - & - \\
Peru & 2 & - & - & - & - \\
Peru/Ecuador/Colombia/ Panama/Costa Rica & 767 & 63 & - & - & - \\
American Samoa & 446 & 1 & - & - & - \\
Tahiti & 1 & - & - & - & - \\
Tonga & 18 & - & - & - & - \\
New Zealand & 1 & - & - & - & - \\
French Polynesia & 1 & - & - & - & - \\
Madagascar & 226 & - & - & - & - \\
E Australia & 7 & 3 & - & - & - \\
W Australia & 242 & 5 & - & - & - \\
\hline
\end{tabular}

resighted off South Georgia (Sector II), representing the first documented photo-id link between the Brazilian breeding ground and any high-latitude feeding area (Stevick et al., 2006). A second individual was resighted off Madagascar, demonstrating long distance movement of a female between two widely separated breeding areas, a minimum distance of almost $10,000 \mathrm{~km}$ and the longest documented movement by a mammal (Stevick et al., 2010). Two individuals from American Samoa were resighted in the Antarctic Peninsula, documenting the first known feeding area for this central South Pacific Ocean stock. One of these individuals was identified twice in the Antarctic Peninsula setting a round trip seasonal migration record of almost $19,000 \mathrm{~km}$, spanning 108 longitudinal degrees (Robbins et al., 2011). Resightings also include three matches between Antarctic Area V and eastern Australia (Rock et al., 2006), supporting earlier evidence provided by Discovery tags linking these two areas (Dawbin, 1966).

\section{DISCUSSION}

The AHWC provides a powerful non-lethal and noninvasive tool for investigating the movements and population structure of the whales utilising the Southern Ocean Sanctuary. Through methodical, coordinated comparison and maintenance of collections from across the hemisphere, large-scale movement patterns may be examined, both within the Antarctic, and from the Antarctic to breeding grounds at low latitudes. Effort continues to stimulate submission of opportunistic data from the International Association of Antarctica Tour Operators (IAATO) cruise ships in the Southern Ocean and directed samples from research organisations and expeditions working throughout the Southern Hemisphere.

The catalogue has expanded dramatically in recent years. As all new individuals are added to the growing catalogue, the temporal as well as the geographic scope of the

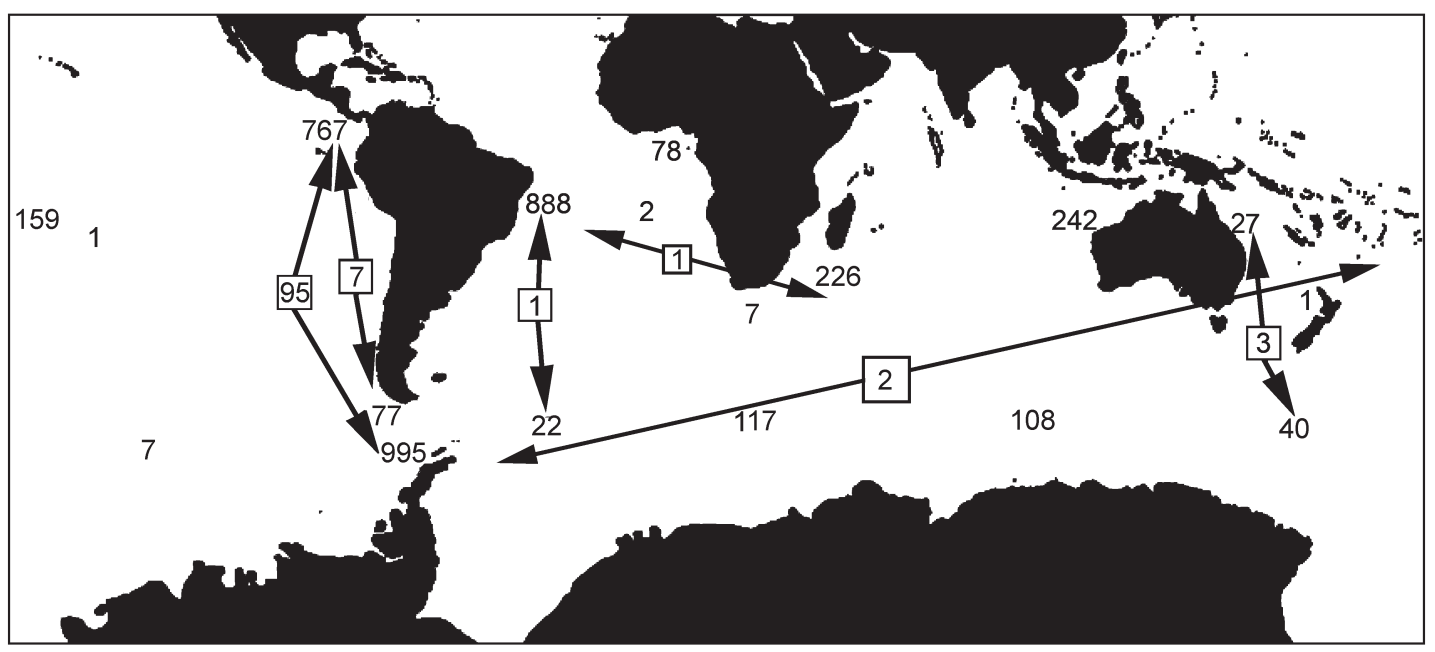

Fig. 1. Distribution of individual humpback whales identified by fluke photographs contained in the AHWC. Arrows and corresponding boxed figures represent the number of individuals resighted between habitats. 
collections continues to grow. Increasing awareness of the project among research organisations, tour operators and other organisations has widened the scope of the collection; research efforts in areas that had not previously been sampled have extended the geographic coverage. In addition, the collections of several long-term contributors have expanded substantially, accounting for significant additions of photographs. Thus, the catalogue has almost doubled in size over recent years.

The AHWC is a valuable tool for the facilitation of international collaboration in humpback whale research. With continued expansion, the collection can make substantial contributions towards and understanding of the population ecology of humpback whales in the Southern Hemisphere through examination of broad-scale movements.

\section{ACKNOWLEDGEMENTS}

This project would not be possible without the participation of the many scientists, naturalists and tourists who, in the spirit of international collaboration, have contributed photographs. We are indebted to them all for their generosity and support. An enormous number of technicians and students have contributed to the cataloguing effort over many years. Special thanks to B. Holm, P. Olson and J. Rock for their hard work and dedication to this project. S. Katona and G. Stone were instrumental in getting the catalogue started. The International Whaling Commission and the Abercrombie and Kent Global Foundation provided crucial continuing support.

\section{REFERENCES}

Dawbin, W.H. 1966. The seasonal migratory cycle of humpback whales. pp.145-70. In: Norris, K.S. (eds). Whales, Dolphins, and Porpoises. University of California Press, Berkeley and Los Angeles. xv+789pp.

Friday, N., Smith, T., Stevick, P. and Allen, J. 2000. Measurement of photographic quality and whale distinctiveness for the photographic identification of humpback whales. Mar. Mammal Sci. 16(2): 355-74.
Friday, N.A., Smith, T.D., Stevick, P.T., Allen, J. and Fernald, T. 2008. Balancing bias and precision in capture-recapture estimates of abundance. Mar. Mammal Sci. 24: 253-75.

Katona, S.K. and Beard, J.A. 1990. Population size, migrations and feeding aggregations of the humpback whale (Megaptera novaeangliae) in the western North Atlantic Ocean. Rep. int. Whal. Commn (special issue 12): 295-305.

Katona, S.K. and Whitehead, H.P. 1981. Identifying humpback whales using their natural markings. Polar Rec. 20: 439-44.

Rasmussen, K., Palacios, D., Calambokidis, J., Saborio, M.T., Dalla Rosa L., Secchi, E.R., Steiger, G.H., Allen, J.M. and Stone, G. 2007. Southern Hemisphere humpback whales wintering off Central America: insights from water temperature into the longest mammalian migration. Biology Letters 3(3): 302-05.

Robbins, J., Dalla Rosa, L., Allen, J.M., Mattila, D.K., Secchi, E.R., Friedlaender, A.S., Stevick, P.T., Nowacek, D.P. and Steele, D. 2011. Return movement of a humpback whale between the Antarctic Peninsula and American Samoa: a seasonal migration record. Endang. Species Res. 13: 117-21.

Rock, J., Pastene, L.A., Kaufman, G., Forestell, P., Matsuoka, K. and Allen, J. 2006. A note on East Australia Group V Stock humpback whale movement between feeding and breeding areas based on photoidentification. J. Cetacean Res. Manage. 8(3): 301-05.

Stevick, P.T. 2005. Stock identity of humpback whales near the Antarctic Peninsula: evidence from movement of naturally marked individuals. Paper SC/57/SH2 presented to the IWC Scientific Committee, June 2005, Ulsan, Korea (unpublished). 6pp. [Paper available from the Office of this Journal].

Stevick, P.T., Aguayo, A., Allen, J., Avila, I.C., Capella, J., Castro, C., Chater, K., Dalla Rosa, L., Engel, M.H., Felix, F., Florez-Gonzalez, L., Freitas, A., Haase, B., Llano, M., Lodi, L., Munoz, E., Olavarria, C., Secchi, E., Scheidat, M. and Siciliano, S. 2004. Migrations of individually identified humpback whales between the Antarctic peninsula and South America. J. Cetacean Res. Manage. 6(2): 109-13.

Stevick, P.T., Neves, M.C., Johansen, F., Engel, M.H., Allen, J., Marcondes, M.C.C. and Carlson, C. 2010. A quarter of a world away: female humpback whale moves $10,000 \mathrm{~km}$ between breeding areas. Biol. Letters October 13, 2010: doi: 10.1098/rsbl. 2010. 0717.

Stevick, P.T., Pacheco de Godoy, L., McOsker, M., Engel, M.H. and Allen, J. 2006. A note on the movement of a humpback whale from Abrolhos Bank, Brazil to South Georgia. J. Cetacean Res. Manage. 8(3): 297-300.

Stevick, P.T., Smith, T.D., Bravington, M.V., Palsbøll, P.J. and Hammond, P.S. 2001. Errors in identification of individuals by natural markings: rates, sources, and effects on capture-recapture estimates of abundance. Can. J. Fish. Aquat. Sci. 58: 1861-70.

Stone, G.S., Flórez-González, L. and Katona, S. 1990. Whale migration record. Nature 346: 705-06.

\section{Appendix 1 \\ TERMS OF USE AGREEMENT}

By accepting this document and using the Antarctic Humpback Whale Catalogue (AHWC) the User agrees to the following.

(1) Not to use data contained in the Antarctic Humpback Whale Catalogue (AHWC) in any publication, product, or commercial application without prior written consent of the original data provider.

(2) To cite both the data provider and the Antarctic Humpback Whale Catalogue (AHWC) appropriately after approval of use is obtained.

(3) Not to hold the Antarctic Humpback Whale Catalogue (AHWC) liable for errors in the data. While we have made every effort to ensure the quality of the database, we cannot guarantee the accuracy of the data. 